\title{
US satellite monitoring comes under siege
}

Washington. US Earth scientists are growing increasingly concerned that budget hawks in the US House of Representatives have seized on the Earth Observing System (EOS) of the National Aeronautics and Space Administration (NASA) as a likely place to find savings. NASA programme managers fear funding for the space-based environmental monitoring network may be reduced for the fourth time in three years.

The House Budget Committee, which is leading the drive to cut government spending, recently included EOS in a series of suggested cuts (see Nature 374, 293; 1995). That recommendation followed a report in February on options for reducing the deficit by the Congressional Budget Office (CBO). In particular, the CBO suggested the government could save $\$ 326$ million over five years by delaying the launch of the third of EOS's three principal satellites, CHEM-1, and cutting the EOS data and information system (EOSDIS) by 25 per cent.

"Scientists do not expect EOS to pro- Eye in the sky: AM-1 is due for launch in 1998. vide data and analysis to support environmental policy decisions over the next decade," said the CBO. "Thus the loss of benefits from deploying the [CHEM] satellite in 2007 instead of in 2002 is arguably small." The first large EOS payload, called AM-1, is due to launch in 1998.

The House Science Committee, led by Robert Walker (Republican, Pennsylvania) is also looking closely at EOS, and has ordered an audit of the project by the General Accounting Office (GAO), to be completed this summer. Testimony by a GAO auditor before the committee's space subcommittee earlier this month suggests that the report's thrust will be critical.

EOSDIS, the system being set up to collect, archive and distribute EOS data, came in for some especially harsh words. "NASA still has not given adequate attention to EOSDIS users, their expectations, or their needs," said the GAO in its testimony. It added that the agency should pay more attention to testing small-scale prototype systems, rather than concentrating on building the complete EOSDIS.

Many scientists also worry about the magnitude of that task. But NASA officials, as well as the project's outside advisers, say GAO's criticisms are either outdated or wrong. Dixon Butler, NASA's manager for the EOSDIS system, points out that several prototype projects are already under way. He says the data needs of Earth scientists are now fairly well understood; "where we need to do more, and are doing more, is with the non-science users," he adds.

Much of the latter task falls to the Consortium for International Earth Science Information Network (CIESIN) in Michigan, which has itself been the subject of con- troversy. Established in 1989, the centre has been widely seen as a 'pork-barrel' project for former Michigan congressman Bob Traxler, who once headed NASA's budget panel. Acting on a recommendation by the Clinton administration, Congress this year rescinded \$27 million in previously allocated funds for a new CIESIN building in Traxler's home state (see page 401). Now, says Butler, "the pork is gone."

But the job of encouraging more non-scientific use of EOS data remains. That has

\section{IMAGE UNAVAILABLE FOR COPYRIGHT REASONS}

put a large strain on the system, says Charles Zraket, the former president of Mitre Corporation who chaired a National Research Council study of EOSDIS last year. "There's been a horrendous increase in the number of people who want access to these [EOS] data," from educators to policy-makers to environmental groups, he says.

If EOSDIS continues receiving less money to serve more people, Zraket fears the science community's needs will be neglected. "The scientists feel that one of the reasons EOSDIS costs are so high is that it's trying to serve all these people," he says.

EOS managers at NASA are now talking to the National Oceanic and Atmospheric Administration, which runs US weather satellites, about coordinating their datamanagement systems in order to bring further economies to EOSDIS. But this is not likely to make up for a large budget cut, should one occur. Nor would a plan to incorporate limited amounts of Russian remote-
Washington. The Mexican Academy of Scientific Research has announced the creation of a National Research Foundation, planned to help the government make decisions on a range of issues concerning science, technology, and public health.

The new body will be organized in a similar way to the US National Research Council (NRC), the working arm of the National Academies of Science and Engineering. Its Mexican equivalent will work through committees of expert sensing data into the system, which is expected to be on the agenda at the next meeting between $\mathrm{Al}$ Gore, the US Vice President, and Viktor Chernomyrdin, the Russian Prime Minister, this summer.

Another idea that is unlikely to help, at least in the near term, would be to 'privatize' the EOS data system. Senior NASA managers have suggested this as a way to cut the costs of EOSDIS, and Walker has shown interest in the idea in Congress. But most scientists doubt whether there is sufficient

o commercial potential for EOS data, at

畄 least at this early stage. "If there were a market here, a real stand-alone market, I'd be out there trying to capture it," says Butler.

The fact that the idea of privatization 蛋 is taken seriously, however, shows that many in Congress are uneasy about the programme, and are looking for alternatives. The House space subcommittee even invited the physicist Edward Teller to testify recently about his idea for a constellation of hundreds of small Earthviewing satellites, based on space-based missile defence concepts.

The perception that EOS technology is already outdated before its first launch is only one political liability. Another is the fact that the project's focus on environmental science does not endear it to Republicans in Congress. Nor does its open-ended price.

What started in 1991 as a \$17-billion programme has shrunk to a one costing $\$ 7.2$ billion. But that covers its costs only up to the year 2000 , and the programme is designed to last at least 15 years in order to provide long baseline measurements of the solid Earth, atmosphere and oceans.

One bright spot for EOS is that it has a powerful champion in the Senate, Barbara Mikulski (Democrat, Maryland). NASA's Goddard Space Flight Center, where much of the agency's work on EOS is done, is in Mikulski's home state - and she is therefore likely to keep close watch over the project as the budget hawks circle.

Tony Reichhardt

\section{Mexican academy plans research arm}

scientists who will examine issues of importance to the country and prepare reports on their conclusions.

The proposal to establish the new body emerged from a joint study of Mexico City's water supply by Mexican and American scientists, and organized by the NRC. According to Mauricio Fortes, president of the Mexican Academy of Science, the experience gained during this convinced the academy it would be valuable to have an interdisciplinary organization working along the same lines. 